\title{
Technology of dehydration and transformation of silicic acid
}

\author{
Xiao-Cai He*, Gang Xie, Hui-Re Li, \\ Rong-Xing Li, Da-Jin Yang, Qing-Xin Xu
}

Received: 23 July 2012/Revised: 12 October 2012/ Accepted: 20 October 2012/Published online: 20 August 2013

(C) The Author(s) 2013. This article is published with open access at Springerlink.com

\begin{abstract}
The technology that silicic acid was pressurized under high temperature in order to dehydrate and transform was investigated in the paper. The effects, such as the ratio of liquid to solid, pressure, temperature, and reaction time on the dehydration rate and volume shrinkage rate, were researched. The experimental results show that the dehydration rate of silicic acid is up to $41.20 \%$, accompanying with the volume shrinkage rate of $40.37 \%$ after silicic acid is pressurized under high temperature in the high-pressure kettle. The results of silicic acid tested by SEM indicate that the metasilicate acid molecules and water molecules are closely arranged, and there are almost no gaps before pressure reaction. There are many gaps accompanying with formatting lamellar structure after pressure reaction. The experimental results indicate the effect that silicic acid is dehydrated and transformation is obvious under high temperature and pressure.
\end{abstract}

Keywords Silicic acid; Pressurized; Dehydration; Transformation

\section{Introduction}

Silicic acid is important raw materials for high-purity quartz, light-guide fiber, metallurgical polycrystalline

X.-C. He*, G. Xie, R.-X. Li

Faculty of Metallurgical and Energy Engineering, Kunming University of Science and Technology, Kunming 650051, China e-mail: hexiao-cai@163.com

X.-C. He, G. Xie, H.-R. Li, D.-J. Yang, Q.-X. Xu Department of Metallurgical Researching, Kunming Metallurgy Research Institute, Kunming 650031, China silicon, and refractory materials [1-3]. On the one hand, silicic acid is used as catalyst or catalyst carrier in petroleum, chemical industry, synthetic fiber, synthetic rubber, and so on [4-6]. It is also a better kind of adsorbent, desiccant, or moisture proof agent [7-10]. On the other hand, silicic acid is also utilized as filling material or reinforcing material $[11,12]$. More importantly, it is a kind of inorganic salt industrial products. But silicic acid has some obvious shorts, such as many pore structure and containing water of crystallization [13]. Silicic acid usually contains about $70 \%-75 \%$ water [14], which not only increases cost of transportation and raw materials but also limits the usage of silicic acid.

Silicic acid was decomposed out from sodium silicate solution through carbonating process and acid pickling process, which usually had about $70 \mathrm{wt} \%-75 \mathrm{wt} \%$, so the technology that silicic acid was pressurized under high temperature and pressure in order to dehydrate and transformation was investigated in the paper. Owing to the high temperature and pressure, some of the crystal water could be removed quickly and easily accompanied the destructing and recombining processes of the crystal lattice of silicic acid. According to this principle, we researched the process that silicic acid was dehydrated and transformed under high temperature and pressure in order to get a simple and low-cost process.

Nevertheless, the dehydration method of silicic acid was mainly related to the high-temperature technology under 700-900 ${ }^{\circ} \mathrm{C}$ at home and abroad [15]. Researches of this kind had some shortcomings such as high energy consumption and high absorbent water. At the same time, there are few papers about the conditions for the dehydration and transformation process of silicic acid under high pressure, so studying the technology of dehydration and transformation under high pressure is necessary. 


\section{Experimental}

\subsection{Raw materials and instruments}

The silicic acid utilized in this study originated from sodium silicate solution by carbon dioxide decomposition, and it was washed to remove the surplus impurities by hydrochloric acid. The chemical compositions of silicic acid are shown in Table 1. It was indicated that the impurities, such as $\mathrm{Al}, \mathrm{Fe}, \mathrm{Ti}, \mathrm{Cu}, \mathrm{Zn}$, and $\mathrm{Mn}$, were very low, but the moisture was about $75 \%$.

The instruments and equipments used in the test are as follows: high-temperature reaction kettle of titanium material, water bath reactor, speed blender, atomic absorption spectrophotometer (P2E3030), and inorganic mass spectrometry (ICP2MSEIAN2750).

\subsection{Experimental method}

The experimental method in this study is that silicic acid and pure water were put into the high-pressure kettle after mixing according to a certain ratio of liquid to solid, and the effects, such as the ratio of liquid to solid, pressure, temperature, and reaction time on the dehydration rate and volume shrinkage rate, were researched. After that, the volume shrinkage rate and the dehydration rate of the silicic acid were tested, and also, the crystal lattice change of silicic acid was tested by the analysis of SEM.

\subsection{Calculation method of dehydration rate and volume shrinkage rate}

The dehydration rate of $\mathrm{H}_{2} \mathrm{SiO}_{3}$ is based on the following equation:

$Y_{1}=\left(M_{1}-M_{2}\right) / M_{1} \cdot 100 \%$

The volume shrinkage rate of $\mathrm{H}_{2} \mathrm{SiO}_{3}$ is based on the following equation:

$Y_{2}=\left(V_{1}-V_{2}\right) / V_{1} \cdot 100 \%$

where $M_{1}$ and $M_{2}$ are moisture content of $\mathrm{H}_{2} \mathrm{SiO}_{3}$ before and after dehydration and transformation, respectively. $V_{1}$ and $V_{2}$ are volume of $\mathrm{H}_{2} \mathrm{SiO}_{3}$ before and after dehydration and transformation, respectively.

\section{Results and discussion}

\subsection{Effect of temperature}

The experiment conditions were carried out as follows: $\mathrm{H}_{2} \mathrm{SiO}_{3}$ was $200 \mathrm{~g}$, the liquid-solid ratio, pressure, and reaction time were set as $6: 1,0.8 \mathrm{MPa}$, and $3 \mathrm{~h}$, respectively. The effect of temperature on the dehydration rate and volume shrinkage ratio of $\mathrm{H}_{2} \mathrm{SiO}_{3}$ is shown in Fig. 1. It shows that the dehydration rate of $\mathrm{H}_{2} \mathrm{SiO}_{3}$ increases with the temperature rises. The dehydrating rate that was maintained between $37.5 \%$ and $38 \%$ has a slight increase when the temperature is between 150 and $170{ }^{\circ} \mathrm{C}$. The stable structure is formed between metasilicic acid molecule and crystal water molecule, so it is hard to destroy the high bonding energy. Then, the dehydration rate of $\mathrm{H}_{2} \mathrm{SiO}_{3}$ begins to increase again when the temperature reaches up to $170{ }^{\circ} \mathrm{C}$ because the bond between hydrochloric acid molecule and crystal water molecule may be destroyed. Besides, the volume shrinkage ratio of $\mathrm{H}_{2} \mathrm{SiO}_{3}$ also increases as the temperature increases before $140{ }^{\circ} \mathrm{C}$, and then, a stable area between 140 and $150{ }^{\circ} \mathrm{C}$ in the curve increases for the stable bond and the nearly unchangeable distance between hydrochloric metasilicic acid molecule and crystal water molecule. However, when the temperature increases above $150{ }^{\circ} \mathrm{C}$, the distance between

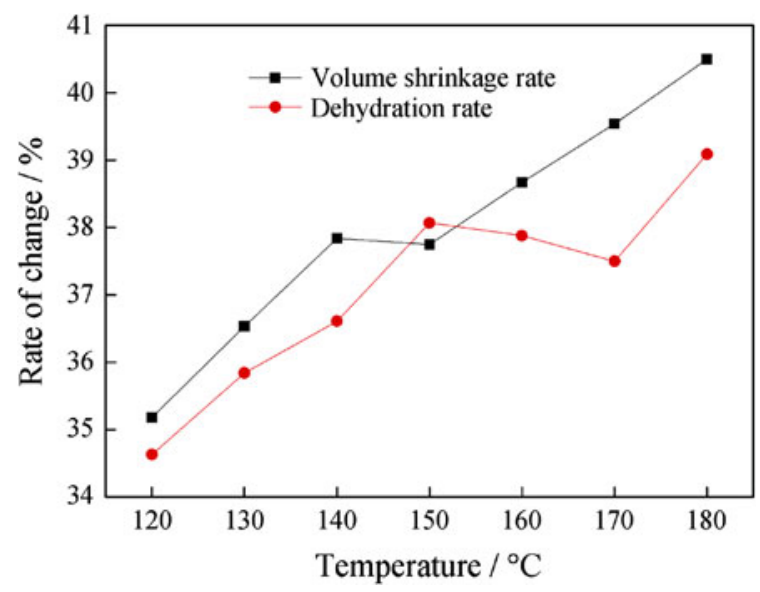

Fig. 1 Effect of temperature on dehydration rate and volume shrinkage rate of $\mathrm{H}_{2} \mathrm{SiO}_{3}$

Table 1 Chemical composition of silicic acid (\%)

\begin{tabular}{llllllll}
\hline $\mathrm{SiO}_{2}$ & $\mathrm{Al}$ & $\mathrm{Fe}$ & $\mathrm{Ti}$ & $\mathrm{Cu}$ & $\mathrm{Zn}$ & $\mathrm{Mn}$ & $\mathrm{H}_{2} \mathrm{O}$ \\
\hline 99.99000 & 0.00200 & 0.00021 & 0.00046 & $<0.00020$ & $<0.000200$ & $<0.0002$ & 75.69000 \\
\hline
\end{tabular}


hydrochloric acid molecule and crystal water molecule may be reduced for the bond destroyed between the two kinds of molecules. Therefore, the suitable temperature range of the transformation and dehydration process is thought to be $150-160{ }^{\circ} \mathrm{C}$.

\subsection{Effect of pressure}

The experimental conditions were carried out as follows: seven samples with the same weight of $200 \mathrm{~g}$ were separately placed under $0.2,0.25,0.3,0.4,0.6,0.7$, and $0.8 \mathrm{MPa}$; the liquid-solid ratio, temperature, and reaction time of all the seven samples were set as $6: 1,150^{\circ} \mathrm{C}$, and $3 \mathrm{~h}$, respectively.

The effect of pressure on the dehydration rate and volume shrinkage ratio of $\mathrm{H}_{2} \mathrm{SiO}_{3}$ is shown in Fig. 2. It is clear that the dehydration rate of $\mathrm{H}_{2} \mathrm{SiO}_{3}$ increases with the pressure rising when the pressure is below 0.4 MPa. The dehydration rate of $\mathrm{H}_{2} \mathrm{SiO}_{3}$ only increases in small extent when the pressure is between 0.4 and $0.7 \mathrm{MPa}$. However, the dehydration rate of $\mathrm{H}_{2} \mathrm{SiO}_{3}$ begins to increase largely again when the pressure is above $0.7 \mathrm{MPa}$. The reason of the slight increase of the dehydration rate of $\mathrm{H}_{2} \mathrm{SiO}_{3}$ is that the structure of $\mathrm{H}_{2} \mathrm{SiO}_{3}$ could retain stability during 0.4-0.7 MPa, and the bond between hydrochloric acid molecule and crystal water molecule is hard to be destroyed under such a pressure range. However, the dehydration rate of $\mathrm{H}_{2} \mathrm{SiO}_{3}$ begins to increase largely when the pressure reaches above $0.7 \mathrm{MPa}$ for the bond between hydrochloric acid molecule and crystal water molecule may be destroyed.

In addition, the volume shrinkage ratio of $\mathrm{H}_{2} \mathrm{SiO}_{3}$ also increases as the pressure increases. However, the increasing trend of the volume shrinkage ratio is almost as invariant as the dehydration rate for the stable bond and the nearly unchangeable distance between hydrochloric acid

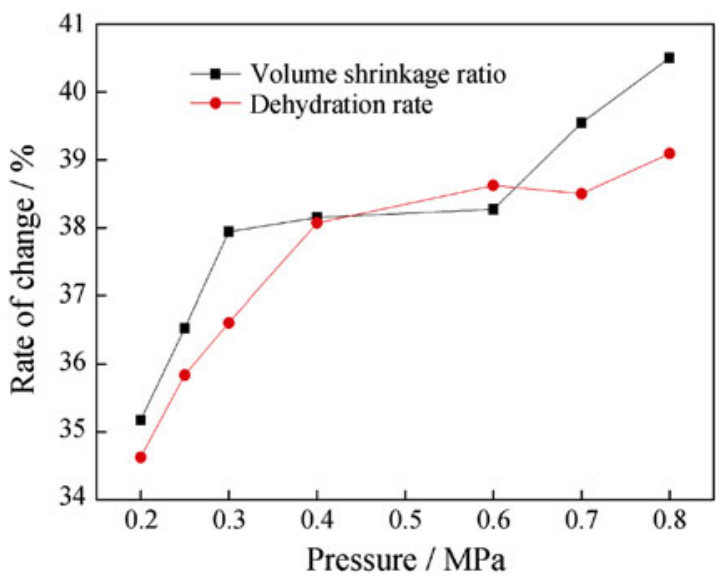

Fig. 2 Effect of pressure on dehydration rate and volume shrinkage ratio of $\mathrm{H}_{2} \mathrm{SiO}_{3}$ molecule and crystal water molecule between 0.4 and $0.6 \mathrm{MPa}$. Then, the volume shrinkage ratio increases again when the pressure increases above $0.6 \mathrm{MPa}$, and the reason may be the distance between hydrochloric acid molecule and crystal water molecule are enlarged by destroying the bond between the two kinds of molecules in this pressure range.

Therefore, the optimal pressure range of the process is thought to be $0.6-0.8 \mathrm{MPa}$.

\subsection{Effect of time}

The experimental conditions were carried out as follows: $\mathrm{H}_{2} \mathrm{SiO}_{3}$ was $200 \mathrm{~g}$; the liquid-solid ratio, pressure, and temperature were set as $6: 1,0.8 \mathrm{MPa}$, and $150{ }^{\circ} \mathrm{C}$, respectively. The effect of time on the dehydration rate and volume shrinkage ratio of $\mathrm{H}_{2} \mathrm{SiO}_{3}$ is shown in Fig. 3, which shows that the dehydration rate and volume shrinkage rate of silicic acid increase with prolonging the reaction time; the dehydration rate and the volume shrinkage rate are, respectively, up to $40.60 \%$ and $40.50 \%$. The bonds between the two kinds of metasilicate acid molecules and water molecules are gradually destructed under the conditions which show the volume shrinkage rate, and the dehydration rate increases in macro. The result is clear that it is useful to the process of transformation and dehydration to prolong reaction time. Therefore, the optimal reaction time range of the process is thought to be $2.5-3.5 \mathrm{~h}$.

\subsection{Effect of liquid-solid ratio}

The experimental conditions were carried out as follows: $\mathrm{H}_{2} \mathrm{SiO}_{3}$ was $200 \mathrm{~g}$, the reaction time, pressure, and temperature were set as $2.5 \mathrm{~h}, 0.8 \mathrm{MPa}$, and $150{ }^{\circ} \mathrm{C}$, respectively. The effect of liquid-solid ratio on the dehydration

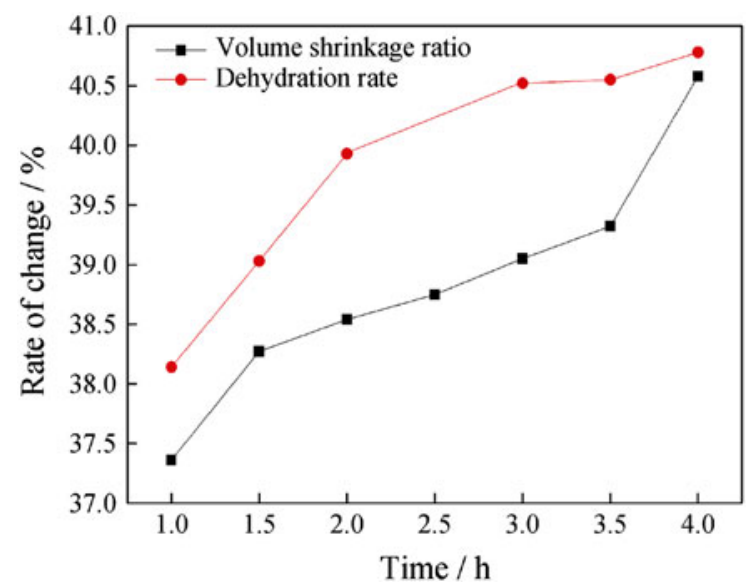

Fig. 3 Effect of time on dehydration rate and volume shrinkage ratio of $\mathrm{H}_{2} \mathrm{SiO}_{3}$ 
rate and volume shrinkage ratio is shown in Fig. 4. It can be seen that the dehydration rate and the volume shrinkage rate increase with the increasing liquid-solid ratio, and they reach their peaks of $41.20 \%$ and $40.50 \%$, respectively. Then, the volume shrinkage rate becomes gentle, and the dehydration rate decreases when the liquid-solid ratio is more than 4.5:1.0. The results show that it is useful to the process of transformation and dehydration under increasing liquid-solid ratio. Therefore, the optimal liquidsolid range of the process is thought to be 3.5:1.0-4.5:1.0.

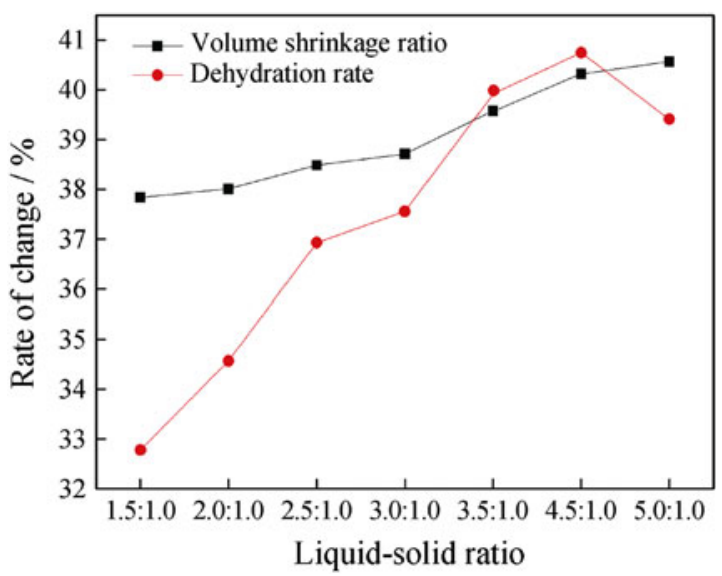

Fig. 4 Effect of liquid-solid ratio on dehydration rate and volume shrinkage ratio of $\mathrm{H}_{2} \mathrm{SiO}_{3}$

\subsection{Experiments under optimum conditions}

Three sets of parallel experiment were conducted according to the preceding experiment results. The experimental conditions were carried out as follows: $\mathrm{H}_{2} \mathrm{SiO}_{3}$ was $200 \mathrm{~g}$, the reaction time, pressure, temperature, and liquid-solid ratio were set, respectively, as $3 \mathrm{~h}, 0.5 \mathrm{MPa}, 150^{\circ} \mathrm{C}$, and 4:1. The results are shown in Table 2.

Table 2 shows that the dehydration rate and the volume reduction rate are, respectively, up to $41.20 \%$ and $40.37 \%$ after pressurizing, which is consistent with the previous results obtained through the same conditions. Since the volume change rate and dehydration rate are very important to the pressurized transition process, samples with dehydration rate of $41.20 \%$ and volume shrinkage rate of $40.37 \%$ were analyzed by SEM, and the results are shown in Figs. 5 and 6.

Figure 5 are the SEM images of water containing silicic acid before pressure. It shows that there are almost no gaps among the silicic acid molecules and the water molecules, and the molecules are tightly packed, but there are many gaps among them, while the lamellar structure is formed after high temperature and pressure (Fig. 6). The main reason is as that the metasilicate acid molecules have lost water molecules under the stated conditions. All these show that the effect that silicic acid is dehydrated and transformed under high temperature and pressure is obvious.

Table 2 Chemical composition of $\mathrm{H}_{2} \mathrm{SiO}_{3}$

\begin{tabular}{llllllll}
\hline Nos. & Temperature $/{ }^{\circ} \mathrm{C}$ & $\begin{array}{l}\text { Pressure/ } \\
\mathrm{MPa}\end{array}$ & $\begin{array}{l}\text { Weight of } \\
\mathrm{H}_{2} \mathrm{SiO}_{3} / \mathrm{g}\end{array}$ & $\begin{array}{l}\text { Volume of } \mathrm{H}_{2} \mathrm{SiO}_{3} \\
\text { (after pressure)/ml }\end{array}$ & $\begin{array}{l}\text { Decreased weight } \\
\text { of } \mathrm{H}_{2} \mathrm{SiO}_{3} / \mathrm{g}\end{array}$ & $\begin{array}{l}\text { Dehydration } \\
\text { rate/\% }\end{array}$ & $\begin{array}{l}\text { Volume shrinkage } \\
\text { rate/\% }\end{array}$ \\
\hline 1 & 150 & 0.50 & 150.9 & 136.9 & 61.10 & 38.96 & 40.37 \\
2 & 150 & 0.50 & 153.4 & 141.8 & 59.60 & 38.01 & 38.17 \\
3 & 150 & 0.50 & 151.9 & 139.5 & 62.91 & 41.20 & 40.37 \\
\hline
\end{tabular}
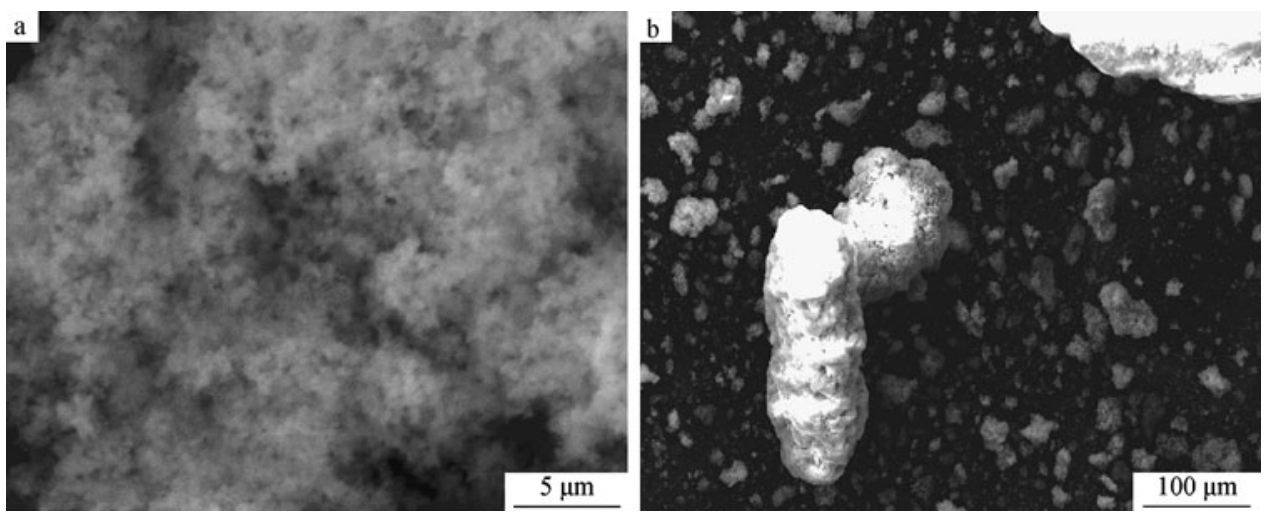

Fig. 5 SEM images of water containing silicic acid before pressure with different magnifications: $\mathbf{a} \times 4000$ and $\mathbf{b} \times 200$ 

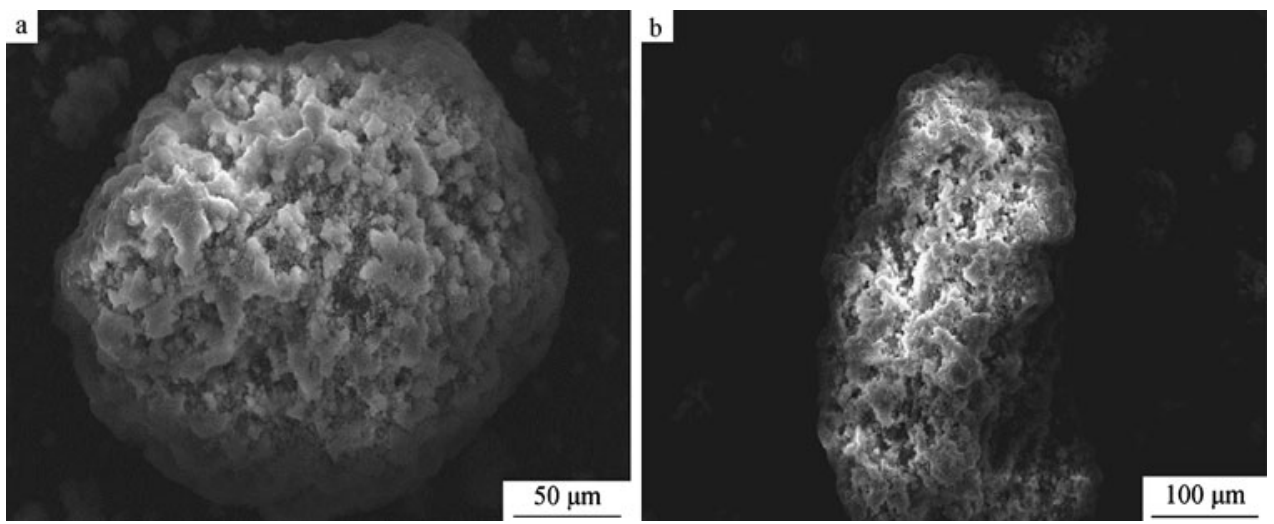

Fig. 6 SEM images of $\mathrm{H}_{2} \mathrm{SiO}_{3}$ after pressure with different magnifications: $\mathbf{a} \times 400$ and $\mathbf{b} \times 200$

\section{Conclusion}

The effect of silicic acid dehydrated and transformed under high temperature and pressure is obvious by controlling the ratio of liquid to solid, reaction temperature, and time. The results show that the dehydration rate and the volume shrinkage rate are, respectively, up to $41.20 \%$ and $40.37 \%$ when the reaction time, pressure, temperature, and the liquid-solid ratio were set, respectively, as $3 \mathrm{~h}$, $0.5 \mathrm{MPa}, 150{ }^{\circ} \mathrm{C}$, and $4: 1$. SEM images of water containing silicic acid before pressure show that there are almost no gaps among the silicic acid molecules and the water molecules, and the molecules are tightly packed, but there are many gaps among them while the lamellar structure are formed after high temperature and pressure. The results indicate that the structure of silicic acid has obviously changed after high temperature and pressure.

Acknowledgments This work was financially supported by the Social Development Plan of Science and Technology-Scientific Research Institute Technology and Development Research Project in Yunnan Province (No. 2009CF011).

Open Access This article is distributed under the terms of the Creative Commons Attribution License which permits any use, distribution, and reproduction in any medium, provided the original author(s) and the source are credited.

\section{References}

[1] Zhu P, Hong D, Wu JH, Qian GR. Kinetics of forward extraction of $\mathrm{Ti}(\mathrm{IV})$ from $\mathrm{H}_{2} \mathrm{SO}_{4}$ medium by $\mathrm{P}_{507}$ in kerosene using the single drop technique. Rare Met. 2011;30(1):1.
[2] Cheng G, Wei XY, Cheng LQ, Liu QS, Wang XC, Sun HY. Effects of $\mathrm{RE}^{3+}(\mathrm{RE}=\mathrm{La}, \mathrm{Ce}, \mathrm{Pr}, \mathrm{Sm}, \mathrm{Dy}, \mathrm{Ho}, \mathrm{Er}$, and Tm) on the luminescence of $\mathrm{Sr}_{2} \mathrm{MgSiO}_{5}: \mathrm{Eu}^{2+}$ phosphors. Rare Met. 2011;30(1):8.

[3] Liu GZ, An Y, Sui ZT. Kinetics of extracting vanadium from HDS spent catalyst by alkali leaching. Min Metall Eng. 2004;24(2):65.

[4] Tromans D. Oxygen solubility in inorganic solutions: concentration, temperature, and pressure effects. Hydrometallurgy. 1998;50(4):279.

[5] Starink MJ. The determination of activation energy from linear heating rate experiments a comparison of the accuracy of isoconversion method. Thermochim Acta. 2003;404(2):163.

[6] Lee HS, Piron DL. Kinetics of alkaline leaching of pure zinc oxide. Chem Eng Commun. 1995;138(10):127.

[7] Qiu ZX, Zhang MJ. Preparation of aluminium master alloy by electrolysis in molten cryolite. Aluminium. 1990;66(6):560.

[8] Qiu ZX, Zhang MJ. Measurement of back EMF and over voltage in aluminium electrolysis. Aluminium. 1985;61(8):563.

[9] Zhang MJ. Anode process in aluminium electrolysis. Chin J Mater Sci Technol. 1988;4(2):801.

[10] Gurna V, Nakajima T, Ohzawa Y. Electrochemical characteristics and structure of surface: fluorinated graphites with different particle sizes for lithium ion secondary batteries. J Fluor Chem. 2001;12(6):223.

[11] Fukuda K, Kikuya K, Yoshio K. Foliates natural graphite the anode material for rechargeable lithium ion cells. J Power Sources. 1997;69(2):35.

[12] Zhang WF, Wang YH, Ma JM. Heat treatment strengthening and its mechanism of large forging for TA15 titanium alloy. Chin J Rare Metals. 2010;34(1):1.

[13] Wang YW, Feng NX, Sun T, You J, Qin J. Mechanism of removing iron phase in Al-Si alloy by natural deposition. Chin $\mathrm{J}$ Rare Metals. 2010;34(1):28.

[14] Cui H, Hou LG, Zhang JS. Microstructure optimization of Fecontained hypereutectic $\mathrm{Al}-\mathrm{Si}$ alloys by $\mathrm{Cr}$-alloying and its mechanism. Chin J Rare Metals. 2010;34(2):178.

[15] Wang GJ, Xiong BQ, Zhang YG, Li ZH, Li PY. Influence of solidification and thermal deformation on microstructure and mechanical properties of 2D70 aluminum alloy. Chin J Rare Metals. 2010;34(3):317. 